\title{
Healing Trauma and Reasserting Identity through Remembrance in Joanne Fedler's The Dreamcloth
}

\section{Md Abu Shahid Abdullah}

The aim of this article is to analyse the role of memory in generating, transmitting and coming to terms with trauma, and the importance of exploring history, and talking about and sharing traumatic events in the process of healing in Foan Fedler's The Dreamcloth (2005). In the novel, Maya's memories of her unrequited lesbian relationship with her beloved Rochel, oppression by the traditional structures of her family and fewish community, her forced marriage with Yankel, and her being raped by him are responsible for her trauma on a personal level, whereas her forced relocation to South Africa in order to flee from the Holocaust is responsible for her trauma on a communal level. Mia, the protagonist and the grand-daughter of Maya, suffers from the transgenerational trauma of her grandmother, is haunted by her ghost, and also symbolically represents the traumatized fewish community. She cannot relate to her own fewish South African identity and thus tries to avoid being reminded of her historical background. Mia recovers from her trauma by exploring her history, solving the riddles of the past and sharing the traumatic memories of the past.

\section{Keywords}

Transgenerational trauma; trauma fiction; repressed memory; marginalization; identity

\section{Introduction}

The Dreamcloth (2005), a family saga by Joanne Fedler, narrates the story of three consecutive generations of a Jewish family which migrated to South Africa just before WWII, and mainly focuses on the theme of the Jewish Diaspora in South Africa. Although the novel covers a time span from the 1920 s to 1994 , its temporal structure is by no means chronological. It alternates between the past and the present, and, more precisely, between three different 
phases of time. Moreover, the novel consists of several narrative strands which jump between various settings, characters and perspectives. It depicts the personal trauma of Maya - the protagonist of the first generational phase of the narrative and a ghost in the subsequent phases where she haunts her granddaughter - arising from the constraints of the patriarchal society, sexual torture and rape by her husband, and a failed lesbian relationship (repressed homosexual inclination). It also depicts the trauma of Mia who is named after her grandmother and who possesses a physical and intellectual resemblance to her grandmother and bears her transgenerational trauma.

On the collective level, the novel depicts the trauma of the forced migration of the European Jewish people to South Africa, their cultural and racial marginalization there, and, most importantly, their torn identities arising from the desire to forget their past. However, Mia realizes that she will be able to get rid of her past trauma only by confronting the past. This act of confronting the past enables her to come to terms with her trauma and to reestablish her (as well as other Jewish people's) shattered identity. The aim of this article is to analyse the role of memory in generating, transmitting and coming to terms with trauma, and the importance of exploring history, and talking about and sharing traumatic events in the process of healing and identity formation. This article will also prove the close association of art and literature with trauma as well as with the process of healing. The characters consider the medium of art a refuge from trauma as it offers a space to express one's feelings, dreams, emotions and wishes, and many of them are precisely engaged with art to obtain the easing of their traumata.

\section{Trauma: Origin, Characteristics and Healing}

The term "trauma" is derived from the Greek traumatizo, which can be translated as "wound". Although originally the term was used to refer to any injury inflicted on the body, later, in medical and psychiatric terminology, it was understood as a wound inflicted not upon the body but upon the mind (Caruth 3). However, it is Freud's earlier essays which played a significant part in defining "psychic trauma as different from and, in principle, unrelated to, physical trauma" (Onega and Ganteau 9). The study of trauma first gained importance after various $19^{\text {th }}$ century wars, especially the Crimean War (1854-1856) and the American Civil War (1861-1865) when soldiers with war experiences started to demonstrate varieties of mental disturbances including 
phobias, nightmares, nervousness, and so on. In the aftermath of World War I, a new term, "shell shock"1 was coined; during World War II, studies in the US started to focus on the term "combat fatigue" ; finally, in the aftermath of the Vietnam War, in the 1970s and 1980s, this concept received growing interest among scholars in various fields and led to the beginning of trauma research and theory. It was in the 1980 s that the American Psychiatric Association (APA) - because of a consistent political campaign by Vietnam veterans - admitted a psychological condition prevailed in soldiers of the Vietnam War, calling it "posttraumatic stress disorder" (PTSD). ${ }^{3}$ The APA acknowledged for the first time that "a psychiatric disorder could be wholly environmentally determined and that a traumatic event occurring in adulthood could have lasting psychological consequences" (Whitehead 4). According to Anne Whitehead, it is at this point that the concept of trauma was transferred from the field of medicine and science to the field of literary studies (4).

In general, trauma refers to a disorder of the mind resulting from traumatic, particularly, horrifying and life-threatening experiences. In her Unclaimed Experience: Trauma, Narrative and History, Cathy Caruth, one of the most prominent contemporary trauma scholars, describes the unassimilated nature of trauma and explains that a traumatic event is experienced "too soon, too unexpectedly, to be fully known and is therefore not available to consciousness until it imposes itself again, repeatedly, in the nightmares and repetitive actions of the survivor" (4). Ruth Leys follows Caruth's statement when she speaks of a disorder or interruption of the victim's memory deriving from the traumatic experience. Her work explains the concept of "dissociation", and she states that "the traumatic events cannot be remembered in the same way as ordinary events, but are instead dissociated from the person's autobiographical memory" (Leys 2). The primary nature of trauma is therefore related to the impossibility of the mind to incorporate the traumatic experience into the victim's ordinary consciousness.

A number of scholars working in the field of psychiatry, psychology, medicine, and even literary studies have described the symptoms and characteristics of trauma. One basic characteristic of individual trauma is the disarray of memory or the act of dissociation where the traumatic memories in the unconscious mind of the victim cannot be eternally repressed. This inability to repress the traumatic memory permanently gives birth to another essential characteristic of trauma: its self-repetition. This self-repetition means that the repressed experiences start to harass the victims and repeat themselves through flashbacks, nightmares, hallucinations, and other invasive phenomena. The 
traumatized individual cannot control the re-experiencing of trauma and is haunted by the experience. The traumatic experience is normally accompanied by the humiliation and overpowering of the victim, ultimately resulting in feelings of powerlessness, shame, guilt, inferiority, fear, anxiety, and, most importantly, an altered perception of oneself and the world. Another symptom of trauma is avoidance, which means that traumatized persons usually evade situations, places and people who remind them of the traumatizing events and who may potentially evoke a flashback or nightmare. Because of the avoidance, the victim loses interest, and the strength to be involved, in activities which he or she enjoyed and valued in the past, and it withdraws him or her from relationships and social interaction and ultimately means social isolation.

From the establishment of trauma research in the 1970s and 1980s, trauma has mainly been studied from an individual psychological standpoint and has not focused much on the collective perspective of it. Regarding various violent events such as massacres, war, slavery, racial violence, colonialism, and other different forms of political and social mass oppressions which affect not only an individual but also the whole community and even the whole nation, it is, however, important to explore trauma collectively as well. It is not exactly clear how far the symptoms and characteristics of individual trauma can be transferred into collective traumatization. Comparing and contrasting the effects of traumatization on individuals and communities, it can be said that collective trauma originates in the experience of an event or a series of events that threaten social values concerning human rights and impose danger on social welfare and survival. In addition, these events are met with helplessness and horror by the group in question, which in turn reflects the reactions of individuals towards traumatic events.

Both individual and collective forms of trauma share the post-traumatic symptom of avoidance. When a group of people suffer from a traumatic event (Jewish people from the Holocaust, slaves from slavery, black African people from apartheid, and such), they do not really want to remember the event and try to ignore their past. However, this avoidance of the past may result in repressed emotions, inability to make plans for the future, and fragmentation of self-identity. It is important to mention that the concrete shape of the traumatization may change over time, and that the trauma experienced by a generation directly may differ from the trauma experienced by subsequent generations (transgenerational trauma). The experience of collective trauma destroys both the internal and external representations of culture and ultimately leads to the collective loss of meaning. With the 
destruction of values, beliefs, roles, and rituals of the oppressed community, its members are left disempowered, disoriented, and unable to make plans for the future. As traumatization causes a loss of meaning and cultural memory which is essential for identity formation - the victimized community suffers from a disruption of collective identity. In the case of oppressive, violent, and traumatic historical events such as the Holocaust, slavery and apartheid, the former oppressor and oppressed remain estranged even long after the end of the traumatic experiences.

Understanding the impact of trauma on memory is complicated by the fact that unproven self-reports often constitute the only possible and accessible data concerning specific historical events. Memories of traumatic events are neither indelible nor error-free. Bessel A. van der Kolk and Rita Fisler divided the effects of trauma on memory functions into four sets: "traumatic amnesia", which involves the loss of memories of traumatic experiences (509); "global memory impairment" which makes it difficult for subjects to construct an accurate account of their present and past history (510); "trauma and dissociation" which refers to memories being stored as fragments and not as unitary wholes (510); and, "the sensori-motor organization of traumatic experience" which states that trauma is organized in memory on sensorimotor and affective levels (512). Trauma affects the building of memory and disturbs the narration of it as well. Since the content of traumatic memory is fragmented, trauma narrative - the narrative of traumatic memory - cannot be unified and linear.

It has already been mentioned that there are contrasting views concerning the fact whether trauma can be worked through and healed or whether it is never-ending and ineffaceable. The present article follows the assumption that trauma can be healed through narration. In trauma studies, numerous scholars have argued of the necessity of transforming traumatic memory into narrative memory through language. The fundamental idea behind this is that by attempting to find words to describe their traumatic experiences, victims regain control over them. Brison opines that the process of narration helps re-establish memory and bring order to the traumatic events until they can be re-integrated into the life narrative of the victim (Brison 71-72). Whereas the experience of trauma is characterized by the powerlessness of the individual - as he or she cannot control the invasive self-repetition of the traumatic events - the conscious narration of the traumatic events implies that the victim slowly regains control over the experiences. Since victims of any traumatic event desire to forget and dissociate themselves from the traumatic 
events, it ultimately creates a sort of torn identity in them. However, through confronting their traumatic past and sharing their traumatic stories with others, victims are able to heal their trauma and to recuperate their severely damaged identity.

\section{Different Layers of Trauma and Distress in Mia's Life}

Soon after her birth, it becomes obvious that Mia has to carry a deep burden that has been passed on to her by her grandmother Maya. Maya has led an unfulfilled life, being forced into a marriage with Yankel, concealing her true sexual inclination and love of the seamstress Rochel, finally escaping from the Holocaust in Lithuania to South Africa. Maya was helplessly forced to leave her true love behind, carrying Rochel's dreamcloth with her, which is then passed on from one generation to the next. Earlier on Mia is haunted by her grandmother restless ghost. Her inherited trauma, inflicted by Maya, manifests itself in different elements. Firstly, she is named after her grandmother, and by sharing the same name, a strong link is created between them. As expressed by Rabbi Goldenberg, who was asked by Maya's parents regarding their despair over her difficulty: "When a child bears the name of an ancestor, there is a link, a very important bond that is created between the two souls. [...] A name is a very powerful force. It is the root of who you are"' (Fedler 134). The Rabbi offers to change Mia's name into a proper Jewish name and suggests the name of Rachel, which embodies another allusion to Maya's secret lover Rochel: "It is your identity - the part of you that has been missing'" (135). Secondly, Mia is also branded by means of her birth-mark - "a pale oval dent on the centre line of her head" (40) - caused by the touch of her grandmother's ghost at birth. Besides her birthmark, she also grows a white patch in her full black hair. Thirdly, Mia also acquires her grandmother's talent for language and words: a special gift for composing poems.

Maya's trauma haunts Mia in the form of oppressive nightmares, always presenting Mia holding a needle, her hand completely covered with blood. Her dreams can be interpreted as referring to Maya's feelings of guilt concerning Rochel's desperate suicide after Maya's forced migration to South Africa. Cathy Caruth refers to Freud's observation of "the unavoidable and overwhelming imposition of historical events on the psyche" (Caruth $5^{8}$ ), which can also be seen in Mia's case, as her nightmares seem to be overwhelming and 
uncontrollable. Because of the appearance of her grandmother, her nightmares can be said to possess an "uncanny" (Herman 41) or even "demonic[sic]" quality (qtd. in Herman 41). Besides her nightmares, Mia is often occupied with cruel stories "about houses burning, babies dying, dogs with one eye, goats that bleed, hearts tearing, limbs in dustbins" (Fedler 116). The intrusions of the past are obvious signs of Maya's torture upon Mia, but they also show the extent of Mia's sufferings from the trauma passed onto her. It is worth pointing out that although Mia is not the direct victim of any grave event which can cause trauma in her (apart from the fact that she does not get motherly affection), she suffers because of transgenerational trauma: because of trauma ignited by events she has never been a direct victim of. Maya, although a direct victim, fails to heal her trauma and Mia, although not a direct victim, bears Maya's trauma and is able to get rid of it. Thus, by healing her own trauma, Mia also heals Maya's trauma. However, referring to Dominick LaCapra, Whitehead states that transgenerational experience of trauma should not be put on an equal plane with firsthand experience of trauma (Whitehead 9).

Since Maya dies with painful memories and fails to find peace even in death, she continues to exist as a ghost with an urgency to speak and starts haunting her granddaughter Mia. Maya haunts Mia as a ghost so that she (Mia) speaks on her (Maya's) behalf and fulfils her unfulfilled desires. She thus passes her trauma originating from various sources - oppression as a woman and a Jew, her forced relocation to South Africa, the separation from Rochel, the rape by her husband and ultimately the loss of her lover - onto Mia. In The Dreamcloth, Fedler mainly transfers the trauma of individual and collective oppression, and the unfulfilled desire from one generation to the next. By letting Maya's ghost haunt Mia, Fedler not only transfers the former's trauma to the latter but also fulfils her unfinished desire.

Mia also suffers from another crucial dimension of her intergenerational trauma - her Jewish heritage - as the narrative claims that Jews are chosen to suffer. As Freud mentions, "Jewish monotheism, as the sense of chosenness, thus defines Jewish history around the link between survival and a traumatic history that exceeds their grasp" (Caruth 67 ). In the course and aftermath of the Holocaust, numerous Jews were persecuted, incarcerated, killed and forced to escape from their home countries. Thus, they often lost connection to their roots, home, culture, language and individual and collective identity: "What does a Jew know from home? Some call them the chosen people, but God 
surely does not love a nation he condemns to such nomadic circumstances" (Fedler 31). Rabbi Goldenberg also points out the chosenness of the Jews to suffer, and their social and political reality while living in South Africa:

I have a theory about South African Jews. I call it 'Destabilized and Detribalized' - it's my own name for what in layman's terms can be called confused identity. Or multiple identities. Don't forget that our ancestors left Eastern Europe, escaping pogroms and anti-Semitism, scattered into the diaspora, and settled wherever they were allowed to stay. South Africa allowed them in. ... We found that we had little in common with the schwarztes [blacks] who hate us because we're white and have a work ethic and contribute to the economy. And on the other hand we had little in common culturally with the Afrikaners who hate us because they think we're all communists. [...] Scapegoats, in the diaspora, lost from the fold, unable to find our way back again. That's the fate of Jews in South Africa. (Fedler 132-133)

The above statement demonstrates that Jews migrating from Europe to South Africa have often experienced a double form of oppression. On the one hand, the Holocaust in Europe demanded racial segregation where Jewish people were forced to leave their home countries; on the other hand, however, these relocated Jews found themselves either with whites or blacks. In addition, Jews in South Africa often struggled to establish their communal identity as they were alienated from the Jewish community in Europe but at the same time found it utterly difficult, if not completely impossible, to consider themselves South Africans. The difficulties in reconnecting with their Jewish roots and affiliating with the South African people create a sort of identity crisis in them which ultimately leads to a collective traumatization. In many instances, this collective trauma was also transferred to the following generations, which still haunts the Jewish people of present-day South Africa. By embodying these circumstances, Mia symbolically represents the traumatized Jewish community. It was mentioned earlier that Mia suffers from permanent restlessness, and struggles to settle in a place: she does not feel comfortable either at home or in any other place in the world. This restlessness and the absence of a home as well as her difficulties in relating to her cultural roots in turn indicate her inheritance of both the transgenerational and collective trauma of the Holocaust and the Diaspora. It concurs with Whitehead's statement that the crisis of individuals goes beyond them "to affect the 
ways in which historical experience can be accessed at a cultural [as well as communal] level" (7).

Laurie Vickroy states that "[t]rauma often involves a radical sense of disconnection and isolation as bonds are broken and relationships and personal safety are put into question. [Victims] feel [unwanted], abandoned or alienated because of their differences with others" (23). Mia has always had a strained relationship with her mother which aggravates her trauma. Because her first pregnancy resulted in miscarriage, Fran (Mia's mother) becomes depressed and traumatized. She did not want any more children and for this reason fails to love Mia: "She had arrived, unwanted, like a disease in her mother's life" (Fedler 298). Because of having a cold and distant relationship with her mother, Mia feels unsafe and cannot rely on her for any help and protection. According to Bowlby, Mia shows signs of "anxious resistant attachment" (124), and she can be said to suffer from total deprivation since her mother is physically present but insensitive to her needs. This troubled relationship with her mother also results in an attachment problem later on in her life where she struggles to rely on other people, and struggles in trusting and becoming close to them. It is because of her fears of being left alone or rejected that Mia fails to establish any sustainable relationship with any man. After her father's death, Mia's restlessness becomes worse, indicating her desire to escape from the past. Instead of mourning her father's death, she tries to run away and wander from one place to another, living the life of a gypsy, in order to avoid dealing with the different layers of her trauma.

\section{Importance of Art and Remembering in Healing Trauma}

The unexpected reunion with the dreamcloth and, consequently, with her father, becomes a turning point for Mia, who now admits her longing and pain, and starts mourning the loss of her father. It is only after getting back her father's dreamcloth that she feels ready to return to South Africa and to face the past. She begins to remember all the pain she has survived, to reconstruct her life and to mourn all the losses involved. She decides to return to South Africa; however, she always carries the dreamcloth with her, close to her heart, accompanying her during this difficult process. Mia seems to be relieved from her guilty feelings, and she experiences her father's love and care again by the means of the dreamcloth. She, now, seems to have accepted her father's 
death, and with the dreamcloth by her side she feels strengthened to face the rest of her traumata. Although she has begun to mourn her father's death, she is still haunted by other events of the past.

Psychotherapists like Dori Laub identify the fact that trauma cannot be faced alone and that healing is possible only "within the context of relationships" (qtd. in Vickroy 22). Mia's meeting up with her mother as well as with her old friends helps her start remembering her past and put together the fragmented pieces of her story. However, it is only after meeting her grandfather Yankel again that she finally receives the truth about Maya and Rochel. A great burden is thus removes from her, relieving her from her grandmother's trauma and paving for her the way to transformation and growth. At Yankel's confession, Mia feels something moving inside her; it is Maya's ghost which is spinning and which finally leaves her: "Mia felt the unravelling of a lifetime's bondage as the umbilicus between her and her ghost spun in giddy spirals separating them to different times and places" (Fedler 312). As Caruth has pointed out, trauma does not necessarily imply "an effect of destruction" but also an "enigma of survival" (Caruth $5^{8}$ ), which can be seen in Mia's case. The book finishes with an open ending but leaves the reader with a positive outlook for Mia's future on a personal level, alluding to a positive outlook for the future of South Africa in general.

According to Herman, recovery from trauma takes place in three stages and we can observe elements of each stage with Mia. The first stage is concerned with the establishment of a sense of safety (Herman 155). Mia feels unsafe and unsettled for a long time until she is handed back the dreamcloth. By accessing to the feelings of her father's love and care, she feels safe enough to face her trauma. The second stage of the recovery includes the resemblance of the past, the reconstruction of one's story (175-176), and the mourning of losses (188). After getting the dreamcloth back, Mia returns to South Africa and slowly makes sense of her past by keeping out her mother and old friends; she even starts mourning the loss of her father as well as other losses in her life. The third and final stage deals with reconnection: referring to the reconnection with oneself and with others. As Mia tries to reconnect with herself by detecting her own history, she also seeks to reconnect with her old acquaintances. She thus experiences some elements of growth, feels more secure than ever before, and looks positively into the future, ready to start a new chapter in her life. By discovering her history, solving the enigma of the past and talking about these events, Mia recovers from her trauma and goes through post-traumatic growth. 
Fedler associates the concept of art and creation (along with remembering and sharing) with trauma and with the whole process of healing. Thereby, the novel addresses different forms of art such as poetry, carving, painting, sewing and music. Throughout her life, Mia tries to cope with her trauma by creating art. Even as a baby, she already has a sense for poetry and she stops crying only when her father reads it to her. Apart from writing poetry, she also creates art by craving little figures from various materials:

In each place, she made her flying figures. Some from driftwood, bequests from the ocean, others from scrap metal she found in the gutters. Not one figure was identical to any other, as if infinity lent itself to this task she had begun in a childhood many lifetimes ago. Some were voluptuous, bosomed, bellied females with tiny wing buds, others were long-bearded skeletal males with penises as long as their outstretched wings, others were blunted, androgynous, with coppery, spiked feathers, arching towards the sun. She always left them behind, a token that she was once there. (Fedler 25)

The fact that these figures all differ from each other raises the suspicion that Mia's figures symbolize humanity and more precisely the Jewish population. Almost all of them have wings so that they can fly away, leave a place behind, and liberate themselves; they, thus, symbolically represent the uprootedness and restlessness of the Jewish population. To phrase it differently, Mia's figures are reminiscent of the Jewish collective trauma. Again, male figures having enormous penises may well symbolize male domination and oppression. Since Mia has always suffered from identity crisis (possessing a torn identity), the creation of these figures enables her to leave a trace in the world. She is always on the run and whenever she abandons a location, she leaves a figure behind to signal that she had once been there. The figures thus anchor her in a place even if she cannot settle there herself.

Firstly, the creation of art can in many aspects be regarded as the direct result of traumatic experience. Mia's poetry, for instance, originates in and reflects upon the transgenerational trauma she inherits from her grandmother Maya. Secondly, the medium of art also functions as a refuge from trauma as it offers a space to express one's feelings, dreams, emotions and wishes. As a place of imagination, art offers comfort to the artist as he or she can see beyond reality and one's traumatic experiences:

Here gypsies, madwomen, angels and crones nattered endlessly to their 
stories of things she had never seen, but had sometimes wished for. And only in this way and at this time did she feel a pulse in her blood, a heat from beneath her apron $[\ldots]$ the whisper of a promise that something existed beyond the stingy pinch of her meagre life. (Fedler 74-75)

Thirdly, art plays a crucial role in relieving trauma; many characters in the novel are precisely engaged with art to obtain this easing of their traumata. The dreamcloth is an important example of such a piece of art which offers comfort to characters such as Maya, Issey, Mia and Asher. Poetry also fulfils the purpose of easing trauma as some characters use it as a source of consolation. Last but not least, Grace's singing is reminiscent of the relieving function of art as her songs take Mia's nightmares away. Most significantly, one of the crucial functions of art is the establishment of a connection and the possibility of communication between different people: art connects Maya and Rochel (who share their art), Maya and Mia (the latter continues the poetry of the former), Yankel and Maya (since he uses her poetry to relate to her), or Mia and Issey (as art leads to the bonding of the two).

\section{Conclusion}

This article has analysed the role of remembrance in the process of recovering trauma (personal and to some extent collective) and of asserting identity in Joanne Fedler's The Dreamcloth. It has proved that unless and until traumatic events are confronted by the victims and shared with others, the healing process will not initiate: remembering is a prerequisite for healing. Mia's coincidental reunion with the dreamcloth prompts her to ponder over her repressed past, and as she confronts her traumatic past events, she seems to be relieved of them. The sharing of her grandmother's secret love story by her grandfather also helps her get rid of her transgenerational trauma, and enables her to develop herself. The article has also shown the significance of having a steady relationship with near and dear ones in the process of healing and identity formation, which is evident from Mia's better relationship with her mother and old friends. Her attempt to reconnect with herself by exploring her own history, as well as with her old acquaintances, provides her with growth and maturity. Last but not least, the article has also shown that the ability to create art enables subjects of trauma to possess self-belief, to ease 
their trauma by connecting with others, and to assert a space for themselves to express dreams and desires and to face the cruelty of outside reality.

\section{Notes}

1. A term coined to describe the reaction of some soldiers in World War I to the trauma of battle. It was a reaction to the intensity of the bombardment and fighting that produced a helplessness appearing variously as panic and being scared, or flight, an inability to reason, sleep, walk or talk (Hochschild 242).

2. A severe reaction, including a set of behaviours resulting from the stress of battle that reduces the fighting skill of the soldiers. Some recurrent symptoms are exhaustion, slower reaction time, dissociation from one's surroundings, and problems in reacting, taking decisions and prioritizing.

3. It is a term consisting of a series of symptoms which follow a psychologically stressful event which is beyond usual human perceptions or experiences. "The symptoms usually manifest as a preoccupation with the traumatic event in the form of nightmares, flashbacks, or persistent thoughts about the trauma that intrude into everyday affairs; and a general dysphoria, a numbness that takes the meaning out of life and makes it hard to relate to other people" (Tal 135).

\section{Works Cited}

Bowlby, John. A Secure Base: Clinical Applications of Attachment Theory. London: Routledge, 1988. Print.

Brison, Susan J. Aftermath: Violence and the Remaking of Self. Princeton and Oxford: Princeton University Press, 2002. Print.

Caruth, Cathy. Unclaimed Experience: Trauma, Narrative and History. Baltimore and London: The Johns Hopkins University Press, 1996. Print.

Fedler, Joanne. The Dreamcloth. Johannesburg: Jacana, 2005. Print.

Herman, Judith Lewis. Trauma and Recovery: The Aftermath of Violence - From Domestic Abuse to Political Terror. New York: Basic Books, 1997. Print.

Hochschild, Adam. To End All Wars: A Story of Loyalty and Rebellion, 1914-1918. Boston, New York: Houghton Mifflin Harcourt, 2011. Print.

Leys, Ruth. Trauma: A Genealogy. Chicago: University of Chicago Press, 2000. Print.

Onega, Susana and Jean-Michel Ganteau. "Introduction." Ethics and Trauma in Contemporary British Fiction. Eds. Susana Onega and Jean-Michel Ganteau. Amsterdam: Rodopi, 2009. 7-19. Print.

Pöschl, Michaela. "Trauma and the Narrative Structure of the Contemporary 
South African Novel." 2011. Web. http://othes.univie.ac.at/14477/1/201105-10_0506703.pdf.

Tal, Kali. Worlds of Hurt: Reading the Literatures of Trauma. Cambridge: Cambridge University Press, 1996. Print.

van der Kolk, Bessel A. and Rita Fisler. "Dissociation and the Fragmentary Nature of Traumatic Memories: Overview and Exploratory Study." Journal of Traumatic Stress. 8.4 (1995): 505-525. Print.

Vickroy, Laurie. Trauma and Survival in Contemporary Fiction. Charlottesville and London: University of Virginia Press, 2002. Print.

Whitehead, Anne. Trauma Fiction. Edinburgh: Edinburgh University Press, 2004. Print.

MD ABU SHAHID ABDULLAH is a Ph.D. Fellow at Otto-Friedrich University Bamberg, Germany. He completed his M.A. in the European Joint Master's Degree in English and American Studies programme from the same university in 2014, including one exchange semester at the University of Graz (Karl-Franzens University) in Austria. In his Ph.D. thesis, he is working on the affiliation between magical realism and historical trauma. Apart from magical realism, he is also interested in Existentialist and Absurdist Literature. He has also taught two undergraduate seminars at the University of Bamberg. He loves travel and learning about various cultures.

jwl_abdullah@yahoo.com 